\title{
AC 2011-2326: S-FIELD ANALYSIS INNOVATION METHOD EXERCISE IN A COMPUTER-INTEGRATED MANUFACTURING COURSE
}

\section{Nebojsa I. Jaksic, Colorado State University-Pueblo}

Nebojsa I. Jaksic received the Dipl. Ing. degree in electrical engineering from Belgrade University in 1984, the M.S. in electrical engineering, the M.S. in industrial engineering, and the Ph.D. in industrial engineering from the Ohio State University in 1988, 1992, and 2000, respectively. From 1992 to 2000 he was with DeVry University in Columbus, OH. In 2000, he joined Colorado State University-Pueblo, where he is currently a professor and the mechatronics program director. Dr. Jaksic's interests include innovation methods, manufacturing processes, automation, and nanotechnology education and research. $\mathrm{He}$ is a member of ASEE, IEEE, SME, and MRS. 


\title{
S-Field Analysis Innovation Method Exercise in a Computer-Integrated Manufacturing Course
}

\begin{abstract}
Developing an ability to innovate in an undergraduate engineering program has been addressed through the theory of inventive problem solving (TRIZ). In particular, an exercise using S-force analysis is developed for a computer-integrated manufacturing course. The exercise deals with an electro-mechanical pneumatic system - a desktop punch press suitable for use in a laboratory environment. First, a preliminary flawed design is analyzed to identify physical contradiction. An S-field analysis is performed so that a new design having the physical contradiction resolved can be proposed and implemented.
\end{abstract}

\section{Introduction}

The Society of Manufacturing Engineers (SME) has predicted that this year the U.S. will lose its world leadership standing in manufacturing. While this fact does not seem to be important today, the consequences are far reaching and may be catastrophic to our nation. Michael Wessel, a member of the US-China Economic and Security Review Commission claimed that "we no longer have the domestic capacity to produce enough ammunition to supply our troops and law enforcement ${ }^{1}$." In his weekly address (October $2^{\text {nd }} 2010$ ) dealing with clean energy projects, President Obama stated that "Our future as a nation depends on making sure that the jobs and industries of the $21^{\text {st }}$ century take root here in America. ${ }^{2 "}$ The innovation productivity and quality combined with the latest technological advances must increase in order to stop the country's technological and manufacturing decline. Currently, most engineering schools are concentrated on educating solid problem solvers. However, this is not enough. The education of engineers, the primary leaders of our innovation based society, must also enhance students' inventive and entrepreneurial skills by including topics on innovation methods, history of innovation, disruptive technologies, intellectual property, entrepreneurship, proposal writing, project planning and control, etc.

By adopting a simplistic view for a moment one can reason that there is a hierarchy that can be established between intelligence, creativity, innovation, and entrepreneurship, where the former is a necessary condition for the latter. In general, intelligence and subject expertise may lead to creating ideas (ideation). Some of these ideas may lead to innovative problem solutions or inventions. Usually, creation of a working physical (sometimes improved) prototype ends the innovation process and starts the entrepreneurial process (commercialization). Creativity, in general, can be quantitatively measured as a number of novel ideas. In engineering, the quality (feasibility) of these ideas also needs to be taken into account. In engineering education research, a number of techniques are implemented to enhance ideation and develop creativity. They include 6-3-5 brainstorming, morphological analysis ${ }^{3}$, transformational design using mindmapping ${ }^{4}$, design by analogy ${ }^{5}$, principles of historical innovators ${ }^{6}$, and various combinations of the aforementioned techniques ${ }^{7}$. Developing an ability to innovate has been approached through improvisation $^{8}$ and the theory of inventive problem solving (TRIZ) ${ }^{9-11}$. 
In engineering education, there are a few engineering design textbooks covering TRIZ to some extent ${ }^{12,13}$. There is a significant body of literature addressing implementations of TRIZ concepts in a number of engineering design courses ${ }^{14-17}$, albeit mostly in mechanical engineering. Lettieri and Yoneyama ${ }^{18}$ address an S-field (also referred to as Su-field) example in electrical engineering. The S-field analysis as an inventive problem solving method is neither well addressed in textbooks ${ }^{12,13}$ nor popular in design courses since it is not easy to teach. The method is relatively broad and based on graphical presentations of physical entities ( $\mathrm{S}$ stands for substance) and physical actions on those substances (fields).

\section{Curricular Context}

At our institution, there are two engineering programs, industrial engineering and mechatronics. Students from both programs are required to take a two course sequence in manufacturing: Engineering of Manufacturing Processes and Computer-Integrated Manufacturing (CIM). The CIM course is a design-oriented course introducing digital logic, sensors, programmable logic controllers (PLCs), automation including pneumatics and hydraulics, computer numerically controlled (CNC) machines, and robots with associated programming languages and packages. Benefits of automation with respect to product quality, efficiency, safety, and cost are emphasized throughout the course. Within the automation module, an S-field analysis exercise is developed. Two class/lab periods are dedicated to the subject of inventive problem solving. Sfield analysis is introduced with a couple of examples from Altshuller ${ }^{19}$.

\section{The Problem}

The problem consists of developing the pneumatic punch press system shown in Figure 1. The system is to operate in the following manner:

1. When an operator presses two pushbuttons at the same time (pushbuttons not shown in Figure 1), the clamping plate pushes down clamping the part to be punched.

2. The punch ram punches through the clamped part and then retracts back to its original position.

3. When the punch ram is fully retracted, the operator releases the two pushbuttons, removes the punched part, inserts the next part, and repeats the process.

A near "closed world" solution is desired, i.e. only minimal modifications to the hardware specification are allowed. This requirement is addressed by asking the students to minimize the cost of the designed system.

\section{Perceived Solution and Physical Contradiction Identification}

Since the students learned how to program using physical ladder logic, they are asked to implement their designs using this knowledge. Most of the designs are similar to the one shown in Figure 2. This exercise takes about 20 minutes to complete. At this time, the students identify the main flow in the design during a discussion with the professor. According to Figures 1 and 2, as the clamping plate clamps the part it also closes LS A thus energizing SOL A, extending the center cylinder, and punching the part through. When the center cylinder extends fully it closes LS B which in turn energizes SOL B. At this time the center cylinder should start retracting the punch. However, this anticipated retraction of the punch does not occur. Since LS A is still closed, SOL A is still energized, thus energizing SOL B does not result in the motion of the spool of the two-position four-way valve which controls the air flow to the center cylinder. In 
fact, if both solenoids (SOL A and SOL B) are allowed to stay energized they could easily overheat due to the high coil current and melt the wire isolation.

The technical contradiction is identified: the center cylinder extends but it does not retract. Even the physical contradiction is often intuitively grasped by the students. The limit switch controlling SOL A should be there when the part is punched but it should not be there while the punch is retracting. Another 20 minutes are set aside for students to try to solve the problem. Here, the students usually try to insert additional rungs and/or relays in the ladder logic diagram to control the function of the two solenoids and therefore the valve. They sometimes try to place an additional limit switch at the starting position of the punch. However, by introducing new elements they increase the cost and decrease the reliability of the designed punch press.

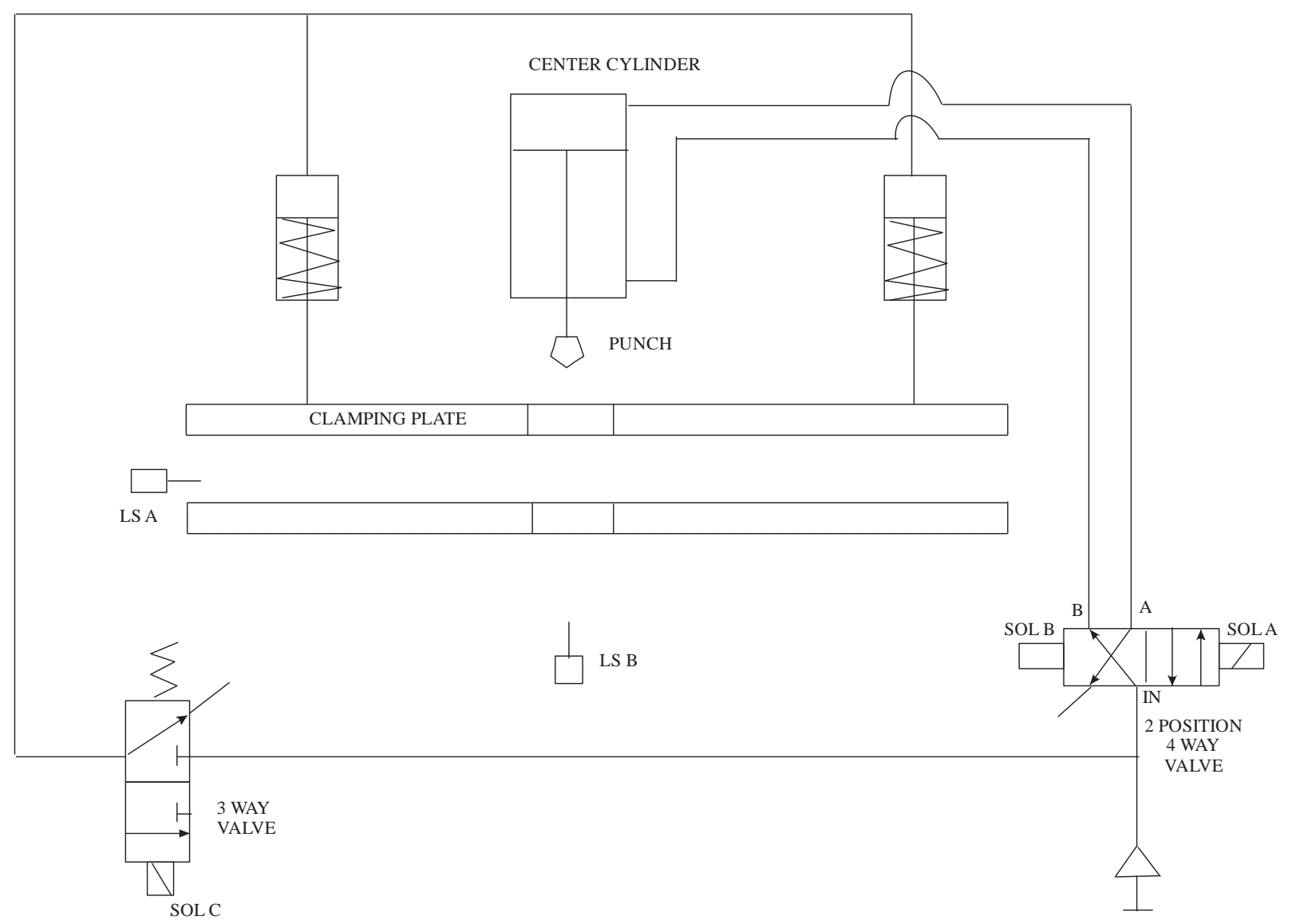

Figure 1. Pneumatic circuit for the punch press design problem

\section{S-field Analysis}

The notion of physical contradiction and S-field analysis are introduced in a short 30-minute lecture. Two examples of physical contradictions and two examples of S-field analyses from Altshuller ${ }^{19}$ are presented. Then the punch press design is revisited. Since LS A should and should not be energizing SOL A, the problem is separated in time. The S-field diagram shown in Figure 3 presents the desired as well as the actual diagram of the problem during the time the center cylinder is extended. 


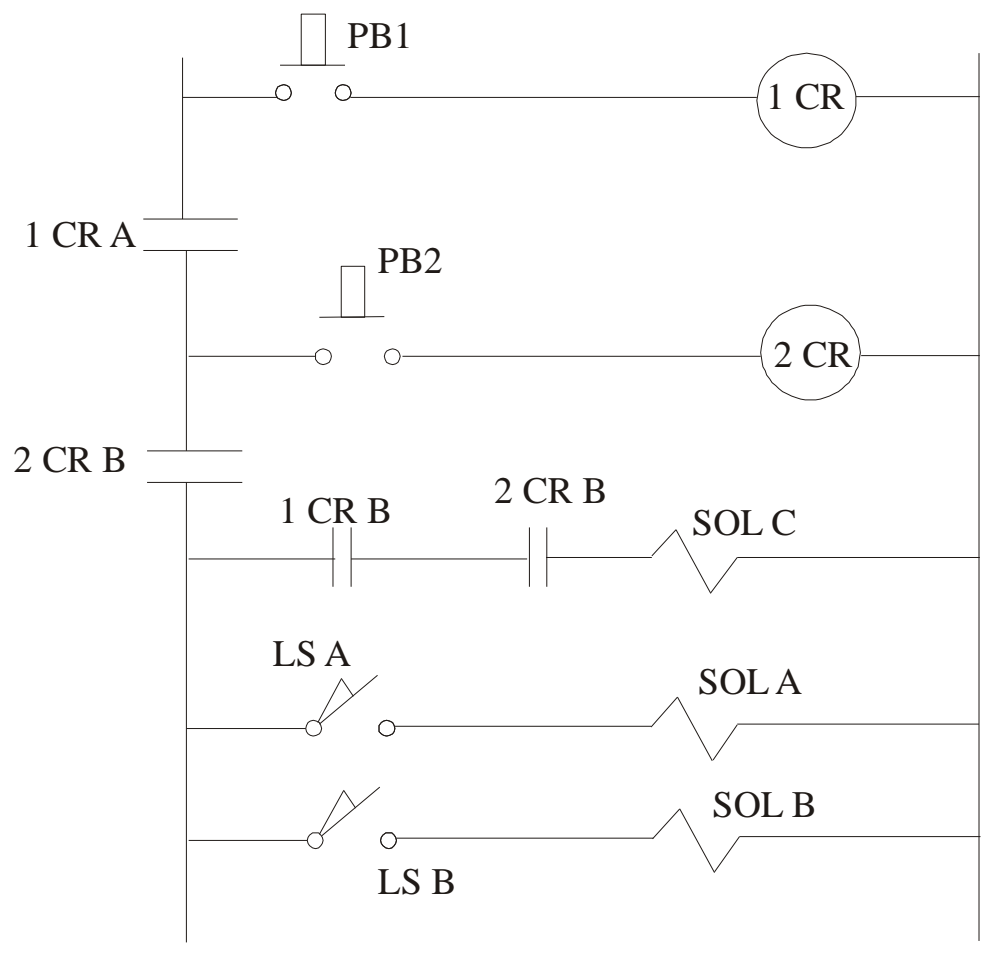

Figure 2. The first solution attempt - physical ladder logic diagram

In the S-field diagram depicted in Figure 3, the physical entities are mapped into substances $\left(\mathrm{S}_{\mathrm{i}}\right)$ and fields $\left(\mathrm{F}_{\mathrm{i}}\right)$. Table 1 presents this mapping for the punch press. Solid arrows in Figure 3 indicate that all the effects are as required by the formulation of the problem.

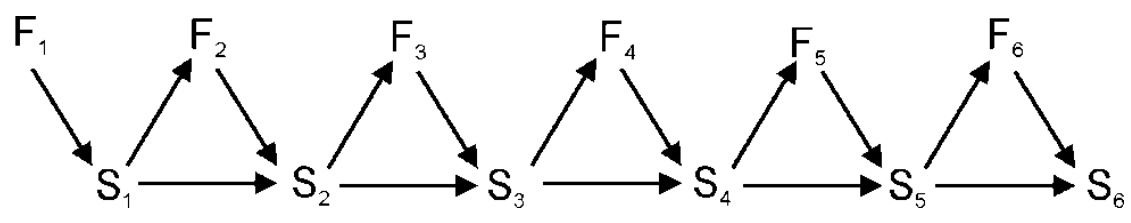

Figure 3. S-field diagram during the time the center cylinder of the punch press is extended and acting on the part

Subsequently, Figure 4 depicts the S-field diagram when the center cylinder is fully extended and the punch has closed LS B. In the figure, wavy lines represent unsatisfactory actions (or interactions) and require a replacement or deletion by the designer. Note that if any of the wavy lines are removed the whole chain will be affected. This is the reason the solid line between $\mathrm{S}_{1}$ and $S_{5}$ is drawn, indicating that the punching process would stop if the clamping action is interrupted.

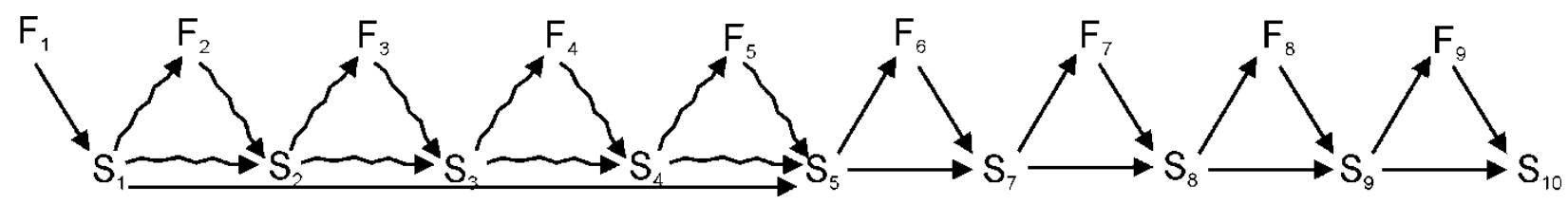

Figure 4. S-field diagram when the center cylinder is fully extended 
Table 1. Mapping of physical entities to substances and fields of Figure 3.

\begin{tabular}{|c|l|c|l|}
\hline Substance & \multicolumn{1}{|c|}{ Physical Entity } & Field & \multicolumn{1}{|c|}{ Physical Entity } \\
\hline $\mathrm{S}_{1}$ & clamping plate & $\mathrm{F}_{1}$ & $\begin{array}{l}\text { pneumatic force acting on the clamping } \\
\text { plate to move it down and clamp the part }\end{array}$ \\
\hline $\mathrm{S}_{2}$ & LS A & $\mathrm{F}_{2}$ & $\begin{array}{l}\text { mechanical force acting on the LS A by the } \\
\text { clamping plate when the part is clamped }\end{array}$ \\
\hline $\mathrm{S}_{3}$ & SOL A & $\mathrm{F}_{3}$ & electrical current energizing SOL A \\
\hline $\mathrm{S}_{4}$ & 2-position 4-way valve & $\mathrm{F}_{4}$ & $\begin{array}{l}\text { electromagnetic force moving the spool of } \\
\text { the 2-position 4-way valve to the right }\end{array}$ \\
\hline $\mathrm{S}_{5}$ & center cylinder with punch & $\mathrm{F}_{5}$ & $\begin{array}{l}\text { pneumatic force moving the center cylinder } \\
\text { down }\end{array}$ \\
\hline $\mathrm{S}_{6}$ & part & $\mathrm{F}_{6}$ & $\begin{array}{l}\text { mechanical force punching through the part } \\
\text { or when the cylinder is fully extended }\end{array}$ \\
\hline $\mathrm{S}_{7}$ & LS B & $\mathrm{F}_{7}$ & electrical current energizing SOL B \\
\hline $\mathrm{S}_{8}$ & SOL B & $\mathrm{F}_{8}$ & $\begin{array}{l}\text { electromagnetic force moving the spool of } \\
\text { the 2-position 4-way valve to the left }\end{array}$ \\
\hline $\mathrm{S}_{9}$ & 2-position 4-way valve & $\mathrm{F}_{9}$ & $\begin{array}{l}\text { pneumatic force moving the center cylinder } \\
\text { up }\end{array}$ \\
\hline $\mathrm{S}_{10}$ & $\begin{array}{l}\text { center cylinder with the } \\
\text { punch moving up }\end{array}$ & & \multicolumn{1}{|c|}{} \\
\hline
\end{tabular}

Figure 5 shows the S-field while the center cylinder is retracting and the punch is not in contact with LS B. This brings an important clue to the problem solution. Once the spool of the 2position 4-way valve is moved to the desired position, the power to the solenoid that performed the action can be removed.

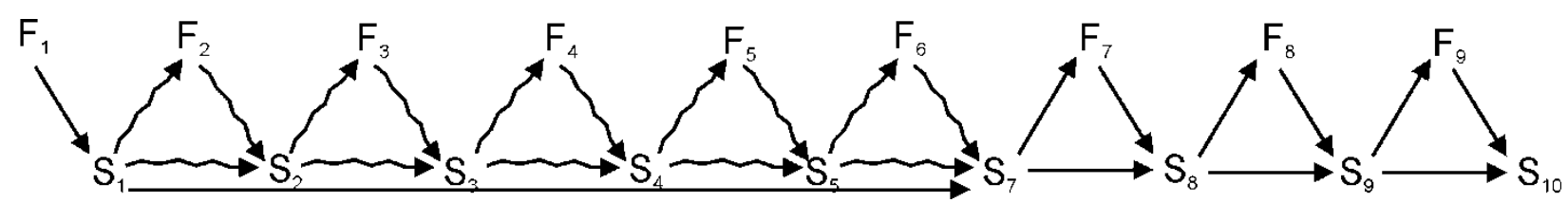

Figure 5. S-field diagram while the center cylinder is retracting and the punch is not in contact with LS B

\section{The Solution}

Figures 4 and 5 indicate that removing any of the undesired interactions would solve the problem. For example, removing the interaction between $S_{2}$ (LS A) and $S_{3}$ (SOL A) when the 
central cylinder is fully extended would break the S-field chain allowing the cylinder to retract. However, to de-energize $S_{8}$ one would require an external component such as a relay. Any solution dealing with the ladder logic diagram would introduce additional parts, and thus is not pursued further. After the above analysis the students turn their attention towards the mechanical portion of the punch press and to the $S_{1}-S_{2}$ interaction in particular. They re-read the design requirements contemplating possible mechanical changes to $S_{1}$ or $S_{2}$. If a satisfactory solution is not obtained within another 10 minutes from the conclusion of the analysis, the students are reminded that (1) $S_{1}$ can interact with $S_{2}$ even before $S_{2}$ finishes its motion securing the part; (2) the part must be secured before it is punched, but that does not mean that the center cylinder has to start moving after the clamping is finished, and (3) $S_{1}$ does not have to be closed for a long time to energize $S_{3}$ and move the spool of the valve. At this point most of the students realize that placing $S_{2}$ just right will solve the problem. $S 2$ should be positioned in such a way so that the clamping plate $S_{1}$ should close $S_{2}$ just before it reaches its clamping position, and should release $S_{1}$ when the clamping position is reached. This breaks the $S_{1}-S_{2}$ interaction as required by $\mathrm{S}$-field chains in Figures 4 and 5. In addition, even the S-field diagram in Figure 3 is scrutinized to achieve the solution.

A laboratory desktop-size setup based on Figure 1 and the presented solution was developed and further enhanced. The two relays in Figure 2 were eliminated. $S_{2}$ was equipped with a thin flexible strip to allow switch activation when the clamping plate moves downwards only.

While the above problem with an associated solution deals with a human-in-the-loop, the total process automation is also discussed whereby the human is replaced by a material-handling manipulator. Economical consequences of the punch press cycle time with and without a human in the loop as well as the waste material created as a byproduct of the punching operation are reiterated.

\section{Summary}

An example utilizing S-field analysis to solve a design problem dealing with an automated punch press is presented. The solution identifies a physical contradiction by separation in time coupled with S-field chains, and then resolves the physical contradiction by employing separation in space. The paper includes a pneumatic circuit for the designed automated punch press and a physical ladder logic diagram for easy adoption. This laboratory-proven system was used for a number of years in an undergraduate engineering program.

\section{References}

1. Tencer, D. "Manufacturing's Decline Threatens National Security, House Panel Hears," The Raw Story, September 22, 2010. Accessed March 10, 2010 from http://www.rawstory.com/rs/2010/09/22/manufacturing-decline-threatens-national-security

2. The White House Press Office, "President Obama's Weekly Address - Oct. 2, 2010," Obama Speeches. Accessed on March 10, 2010 from http://obama-speech.org/transcript.php?obama_speech_id=3798

3. Otto, K., Wood, K., Product Design: Techniques in Reverse Engineering and New Product Development, Prentice Hall, 2001. 
4. Singh, V., Walter, B., Krager, J., Putnam, N., Koraishy, B., Wood. K., Jensen, D. "Design for Transformation: Theory, Method and Application", Proceedings of the IDETC/CIE 2007, ASME 2007 International Design Engineering Technical Conferences \& Computers and Information in Engineering Conference, September, Las Vegas, NV, 2007.

5. Linsey, J., Wood, K., and Markman, A., 2008, "Increasing Innovation: Presentation and Evaluation of the WordTree Design-by-Analogy Method," Proceedings of the ASME Design Theory and Methodology Conference, New York, NY, 2008.

6. Jensen, D. J., Weaver, J., Wood, K. L., Linsey, J., and Wood, J., "Techniques to Enhance Concept Generation and Develop Creativity," ASEE Annual Conference, AC 2009-2369, Austin, TX, June 2009.

7. White, C., Talley, A., Jensen, D., Wood, K., Szmerekovsky, A., and Crawford, R., "From Brainstorming to C-Sketch to Principles of Historical Innovators: Ideation Techniques to Enhance Student Creativity," ASEE Annual Conference, AC 2010-2278, Louisville, KY, June 2010.

8. Ludovice, P., Lefton, L., and Catrambone, R., "Improvisation for Engineering Innovation," ASEE Annual Conference, AC 2010-1650, Louisville, KY, June 2010.

9. Altschuller, G., And Suddenly the Inventor Appeared - TRIZ the Theory of Inventive Problem Solving, Technical Innovation Center, Inc., Worcester Massachusetts, 2001.

10. Clarke, D., Reimer, D., and Ali, A., "A Structured Approach to Innovation: A Classroom Experience in Inventive Problem Solving for an Entrepreneurial Program," ASEE Annual Conference, AC 2009-1349, Austin, TX, June 2009.

11. Camarda, C., Bilen, S., de Weck, O., Yen, J., and Matson, J., "Innovative Conceptual Engineering Design A Template to Teach Innovative Problem Solving of Complex Multidisciplinary Design Problems," ASEE Annual Conference, AC 2010-1733, Louisville, KY, June 2010.

12. Ullman, D. G., The Mechanical Design Process, $4^{\text {th }}$ edition, McGraw Hill, 2010.

13. Dieter, G. E., and Schmidt, L. C., Engineering Design, $4^{\text {th }}$ edition, McGraw Hill, 2009.

14. Rivin, R. I., and Fey, V. R., "Use of TRIZ in Design Curriculum, Innovations in Engineering Education," ABET Annual Meeting Proceedings, pp. 161-164, 1996.

15. Bzymek, A, "Engineering Problem Solving in Design for Manufacturing: Applications of the Brief Theory of Inventive Problem Solving," Tutorial Workshop in 2002 ASME International Design Engineering Technical Conference, 2002.

16. Raviv, D., "Teaching Inventive Thinking, "Recent Advances in Robotics Conference, April 29-30, 1999.

17. Wang, S-L, "Developing a TRIZ Design Tool to Enhance Engineering Design Courses," ASEE Annual Conference, AC 2007-1842, Honolulu, HI, June 24-27, 2007.

18. Lettieri, A. C., and Yoneyama, T., "Su-Field: An Educational Example of Inventive Problem Solving in Electrical Engineering," TRIZ Journal, January 2006.

Available at: www.triz-journal.com/archives/2006/01/05.pdf (accessed 1/19/11)

19. Altshuller, G. S., Creativity as an Exact Science - The Theory of the Solution of Inventive Problems, Gordon and Breach, Science Publishers, Inc. 1984. 